\title{
Demystifying the myth of sensation: Wilfrid Sellars' adverbialism reconsidered
}

\section{Luca Corti ${ }^{1}$}

Received: 8 December 2020 / Accepted: 11 February 2022 / Published online: 7 March 2022

(c) The Author(s) 2022, corrected publication 2022

\begin{abstract}
This paper reconstructs and defends a Sellarsian approach to "sensation" that allows us to avoid mythological conceptions of it. Part I reconstructs and isolates Sellars's argument for "sensation," situating his adverbial interpretation of the notion within his broader theory of perception. Part II positions Sellars's views vis-à-vis current conversations on adverbalism. In particular, it focuses on the Many Property Problem, which is traditionally considered the main obstacle to adverbialism. After reconstructing Sellars's response to this problem, I demonstrate that his position is compatible with some current strategies to solving it and can be developed along similar lines. Finally, part III addresses how a Sellarsian adverbial approach productively accounts for the phenomenal properties of experience often understood to fall under the notion of "sensation". The paper therefore shows how isolating Sellars's argument can yield a non-problematic conception of sensation. Indeed, the argument on which I focus offers a form of direct realism compatible with recent forms of "new adverbialism". Although my view remains Sellarsian, to defend it I maintain that some Sellarsian claims about sensation should be resisted as not logically entailed by his argument.
\end{abstract}

Keywords Sensation · Perception · Sellars · Adverbialism $\cdot$ New adverbialism · Qualia $\cdot$ Ryle $\cdot$ Phenomenal content

\section{Introduction}

"Sensation" is a key notion in both traditional and current philosophical accounts of perception. This "venerable subject" (Peacocke, 1983, p. 4)-long a source of philosophical perplexity-continues to serve as the general heading under which

Luca Corti

luca.corti@unipd.it

1 University of Padua, Piazza Capitaniato 3, 35139 Padova, Italy 
philosophers group their discussions of several basic features of perception. ${ }^{1}$ In particular, the notion of sensation is used to address forms of perceptual "givenness". 2

In this paper, I will focus on the question of whether it is possible to grant sensation a role in theories of perception without conceiving the notion as the name for a mythological Given or raising the set of problems typically related to givenness. To do so, I will draw upon Wilfrid Sellars' attempt to establish a philosophical framework for sensation, reconstructing his argument and mobilizing several of its features in order to develop an account of sensation-not far from Sellars' own-which is amenable to a contemporary, non-problematic philosophical conception of perception. ${ }^{3}$ To isolate the line of Sellars' argument that interests me, I will proceed in three steps.

The first is introductory: before getting into details, I will unpack some of the metaphilosophical assumptions underwriting Sellars' take on sensations. The aim here is to provide the general coordinates for the angle from which he approaches the issue. Sellars notably tends to conceptualize sensation in terms of "conceptual frameworks" (SPR, p. 60). He emphasizes that only by properly understanding the framework under investigation and situating it within a historical (or quasi-genealogical) account of its origins and evolution can we understand when and how things went wrong (and produced our current mistaken interpretations). These general parameters are expressed in a famous passage:

There are two obvious ways in which a philosopher can attack a theory which he believes to be mistaken. He can seek to reduce it to absurdity by developing its implications and showing them to be either mutually inconsistent or incompatible with the incontrovertible. Or he can attempt to trace the error back to its roots, and show why those who defend it have been led to speak as they do. Of these two methods, it is clear that only the latter is capable of definitive results. A mistaken theory can be compared to a symptom of a disease. By the use of inadequate medicaments one can often 'cure' the symptoms while leaving the disease untouched. (P, p. 185)

\footnotetext{
${ }^{1}$ In Peacocke's words (1983, pp. 4-5), many philosophers think that "concepts of sensations are indispensable to the description of the nature of any experience", but "this claim stands in opposition to the view that, while sensations may occur when a subject is asked to concentrate in a particular way on his own experience, or may occur as byproducts of perception, they are not to be found in the mainstream of normal human experience, and certainly not in visual experience.".

2 Characterizations of such givenness can vary dramatically—depending, for instance, on how one describes the phenomenal features associated with sensation and their function in relation to the representational components of experience or conceptual capacities. For an overview, cf. Peacocke (1983, Chap. 1), Crane $(1992,2006)$, as well as Tye (2003) and Lyons (2009, pp. 156ff). Notably, there is no established terminology for "sensation". As will become clear, here I refer to the notion in a sense that is broader than merely the intrinsic (nonintentional), introspective perceptual features of perception.

3 Though Sellars has been considered the great nemesis of givenness, his account of sensation has come under attack even by Sellarsians (cf. McDowell, 2009) and is the least influential part of his thought. I will show that there is a way of looking at Sellars' views that is exegetically underexplored and philosophically interesting for current concerns. For a different treatment of the topic, cf. Levine (2016) and Rosenberg (2000).
} 
In other words, therapeutic correction of mistaken views involves first constructing the right story, or non-problematic framework, for sensation, and then addressing how such a framework got misinterpreted. Part I of the paper will therefore be guided by the following question: what is the appropriate conceptual role for sensation in our framework for perception? My analysis will focus on Sellars' famous account of sensation as a concept belonging to the Manifest Image (MI) framework of perception. Unlike other interpreters, I will argue that it is possible to read Sellars' argument as introducing "sensation" as one part of a larger theory aiming to explain some kinds of overt verbal behavior, not phenomenal properties. In isolating this line of Sellars' thinking, I will emphasize why it should be distinguished from an alternative stance also present in his work that positions phenomenal properties as explananda-and thus bears different theoretical implications.

In part II of the paper, I will focus on Sellars' distinct adverbial understanding of sensation. Standard adverbialism about perception is famous for its theoretical unattractiveness and is generally considered a philosophical dead end. Many scholars have argued against it, and some of its most famous proponents, such as Michael Tye, have later come to reject it. ${ }^{4}$ Sellars is often reductively positioned within this family of accounts and consequently sidelined. However, recent conversation has brought new life to adverbialism, with many authors now defending it as a viable theory. ${ }^{5}$ As I will argue, Sellarsian adverbialism is of a non-standard type. On the one hand, it differs from most well-known, traditional adverbialist accounts (such as Tye's or Ducasse's) and these differences, as I will highlight, enable it to avoid standard objections to adverbialism (including the intentionality of experience). On the other hand, as I will also show, Sellars' adverbialism can profit from current philosophical discussions. This is particularly evident vis-à-vis his solution to the Many Property Problem (MPP), since that philosophical issue is often understood to have dealt adverbialism a fatal blow and therefore has also been at the center of its recent rediscovery. After isolating Sellars' response to this problem, I will assess the compatibility of his views with current positions (especially the account put forth by D'Ambrosio, 2019, 2021).

In the third and final section of the paper, I will focus on phenomenal properties, which are often taken as synonymous with sensation. In light of Sellars' argument-which positions verbal behavior as the primary explanandum for sensation-I argue that phenomenal properties can be accounted for in a way that does not render them problematic. I will thus build off the interpretation of Sellars' adverbial theory isolated and contextualized in the first parts of the paper to show how Sellars' position yields a conception of sensation able to (a) preserve relationality as a basic feature of experience and (b) accommodate the main issues compelling philosophers to introduce "sensation" into accounts of perception (e.g., phenomenal features of perception) without affirming the mythological implications often accompanying the notion. My aim here is twofold: to illuminate a particularly rich line of argument in Sellars' framework and to show how it can be pursued in current philosophical debates.

\footnotetext{
4 Scholars such as Mike Martin ask, "how could anyone have plausibly put forward the adverbialist conception of experience as a serious option, given what we know of our experience?" (Martin, 1998, p. 25). I will try to offer a Sellarsian answer to this question.

5 Cf. D’Ambrosio (2019, 2021), Kriegel (2007, 2008, 2011), Mendelovici (2018, Chap. 9), Banick (2018), Gert (2021).
} 
My general approach in the paper will therefore be to focus on some Sellarsian views while showing how others are not logically implied by the former and can be resisted. The resulting view, which I claim is still Sellarsian, offers a non-problematic form of adverbialism with relevance for current conversations on "sensation". 6 This revised Sellarsian account appears to move in the same direction as current strains of "new adverbialism" (D'Ambrosio, 2019, 2021). Perhaps more surprisingly, it is also compatible with direct realism and, in its analysis of the MI, with the idea that perception is relational in nature.

\section{What is the question to which the notion of "sensation" is the answer?}

In describing the motivations underwriting current theories of perception, Tim Crane notices that

One reason we are provoked to offer a philosophical theory or account of some phenomenon is that the phenomenon is itself intrinsically puzzling, or because some argument is constructed to demonstrate that it is problematic or even impossible. So it is ... with philosophical theories of perception. The sense-data, intentionalist and disjunctivist theories of perception are attempts to answer the apparent contradictions found within the phenomena of perception when we consider certain actual or possible perceptual scenarios. (Crane, 2006, p. 141)

As the passage cited in the introduction shows, Sellars' interest in how theories of sensation are formulated is guided partly by an additional therapeutic aim: to identify and resolve the philosophical puzzles affecting a number of existing theories (especially those advancing what he famously labelled the Myth of the Given and the version of that myth that we might call the Myth of Sensation). ${ }^{7}$

To perform this therapy, Sellars sets out to properly understand the conceptual framework for sensations or sense impressions, analyzing what Gilbert Ryle has called their "conceptual cartography." ${ }^{8}$ In fact, Sellars shares a number of stances with Ryle's metaphilosophical approach—as well as his resulting treatment of "sensation" (Ryle,

\footnotetext{
6 Many of the Sellarsian views I discuss have already been investigated by scholars. See, for instance, Levine (2016), Gupta (2012), DeVries (2005, 2006), Hicks (2020), O’Shea (2007, 2012), Rosenberg (2000, 2007), Richardson and Muilenburg (1982). I will build on this existing analysis in my argument, which has a distinct exegetical component. The exegetical analysis I perform here and the claims I put forth function to disentangle Sellars' views and foreground those of interest to my argument. As will become clear, I follow Sellars' account up to a certain point, while also showing that some of his positions are not logically supported by his premises. I claim that the resulting position is still nonetheless Sellarsian. I am aware that some evidence may seem to contradict this label and respond to this criticism in the final part of the paper. 7 The "myth of the given" (the broadest formulation of which is now identified as "the myth of the categorial given”, O’Shea, 2007, Chap. 7) is probably the most-discussed aspect of Sellars' philosophy (O'Shea, 2021). I will not dwell on it here. It is worth noting, however, that current scholarship on Sellars's metaphilosophy tends to overlook the therapeutic aspects of his reflections and instead focuses on the distinction between the two images in his philosophy (Dach, 2018) or the status of philosophical proposition in his thought (Christias, 2014; Hicks, 2020).

8 Tanney (2013).
} 
1949, 1956) - that helpfully distinguish his approach. ${ }^{9}$ Both Ryle and Sellars consider the endeavor of reconstructing the proper conceptual frameworks for notions such as "sensation" to be the main business of the philosopher. Moreover, both think such reconstructions have therapeutic consequence ${ }^{10}$ and understand such philosophical analysis as not primarily a positive exercise of theory construction but rather a clarificatory endeavor. ${ }^{11}$ Let's call this general attitude the Ryle-Sellars approach to sensation: it aims to tackle issues related to sensation by correctly locating the notion in the appropriate conceptual framework. ${ }^{12}$

More specifically — and this points to another, more substantial point of convergence between Ryle and Sellars-they think the right way of framing sensation is to see it as part of a larger theory. Indeed, both are convinced that "sensation" is a theoretical notion, i.e., one that belongs to a theory or proto-theory developed to account for some phenomena concerning perception. ${ }^{13}$ To explain how this theory was formulated, Sellars presents a "quasi-historical argument, a myth in the platonic sense" (SM, p. 165): the famous myth of Jones. This myth constitutes a rational reconstruction of mentalistic vocabulary in non-mentalistic terms. Its basic outline is by now well know and has been widely explored in the scholarship. ${ }^{14}$ What matters for my purposes is the account the myth offers of the role "the framework of sense impression" (SM, p. 53) plays in our explanation of certain kinds of verbal behaviors: in a community of Ryleian ancestors, who have no concepts or vocabulary for inner episodes (and thus must be conceived as "thinking-out-loud" or performing "candid overt speech"), ${ }^{15}$ sensations are introduced by a mythical theorist, the genius Jones, to account for a case

\footnotetext{
9 Ryle's influence on Sellars' metaphilosophy is pervasive but still has not been investigated in detail. It is beyond the scope of this paper to fully reconstruct it. For our purpose, the parallel is relevant in so far as it helps illuminate Sellars' approach. Here it might be sufficient to note that, in the opening lines of his manifesto Philosophy and the Scientific Image of Man, Sellars conceives philosophy in terms of the self-reflective capacity to understand and orient oneself in conceptual frameworks, and he specifies such a capacity in Ryleian terms as "Knowing one's way around", which "is, to use a current distinction, a form of 'knowing how' as contrasted with 'knowing that", PSIM, p. 1. This is the metaphilosophical view laid out in Ryle's Categories (1938) and applied in The Concept of Mind (1949) and Sensation (1956). Cf. in particular CP, p. 455.

10 Ryle claimed to "hope to help other theorists to recognise our malady and to benefit from my medicine" (COM, p. 1xi).

11 For Sellars' clarificatory aims regarding impression, cf. RA, p. 294 (I will say something more about this below). On Ryle's position, cf. COM, lx.

12 This methodological scaffolding operates under the further assumption mentioned in the introduction that sensation is a historically-laden notion - and thus that the best way of clarifying its content and addressing the errors that have emerged in relation to its various interpretations is to offer a plausible account of its origins (in Sellars" above-mentioned words "why those who defend it have been led to speak as they do"). Such a conceptual account is thought to yield therapeutic effects by dissolving mythological interpretations and exhibiting how they are the products of a series of wrong conceptual turns.

13 Ryle discusses the theory of "postulated sense-impressions" (CP, p. 365), which he sees as formulated under the pressure created by natural-scientific explanations; Sellars, as we will see, also offers a view of sense impression as "postulated by a theory" (SPR, p. 91) and defends an "interpretation of the framework of sense impressions as a theoretical framework" (SM, p. 53). Ryle, however, rejects the postulational framework as a tool for understanding sensations, while for Sellars postulation, correctly interpreted, is constitutive of a proper understanding of the term.

14 Cf. DeVries (2005, 2006), Triplett and DeVries (2006) and O'Shea (2007, 2012) and Garfield (1989). On the idea of telling a "myth" in Sellars' account, cf. Kukla (2000) and Hicks (2020).

15 On this point cf. O'Shea (2007, p. 88ff.).
} 
of hallucination when a member of the community utters "there is X in front of me" but there is no corresponding object (EPM $\$ 60 \mathrm{ff}$.). ${ }^{16}$ Jones provides the explanatory resources to account for this occurrence by postulating that the hallucinator is in a particular state causally linked to her verbal-conceptual behavior. This state is called "sensation" or "sense impression".

Let me stress here that for Sellars hallucinations cause various sorts of behaviors that can potentially have "no detectable verbal output" (EPM, §56). In other words, behaviors can be "silent" (de Vries \& Triplett, 2005, p. 177). However, although such behaviors (broadly understood) eventually constitute part of the explanandum of the Myth of Jones, they are not the primary explanandum. As Sellars stresses in several later texts, the myth aims above all to explain a more specific kind of behavior:

it is part of this general picture that perceptual thinking out-loud, i.e., candid vocal behavior in perceptual contexts, be the primary explicandum in a philosophical analysis of concepts pertaining to perception (SSIS, p. 400, my emph.).

There is thus evidence to support seeing "perceptual thinking out loud" or "candid vocal behavior" as the explanatory target of Jones' theory and candid vocal hallucinatory behavior as the corresponding target of sensations. ${ }^{17}$

After having invented this theory (thereby introducing the new vocabulary of "sensation") to solve the related explanatory demands, Jones then trains members of his community to use it-not only by ascribing sensations to others but also through self-attributions of sensation. Afterwards, Jones "disappeared without a trace" (SM, p. 165). This origin story for "sensation" is only the first part of Sellars' broader approach to perception, but from a Sellarsian perspective it is sufficient to perform the initial therapeutic function of pointing to a plausible non-mentalistic conception of the notion. ${ }^{18}$

A few things are worth noticing at this point before we address Sellars' further elaboration of sensation-which is notably presented in adverbial terms. First, as in classical adverbial theories of perception, in Sellars' myth sensations are introduced through reference to cases of hallucination. Yet unlike classical adverbialism (such as Tye's and Ducasse's), the explanandum is not some property of experience, qualitative feature, or experience itself (generally understood in terms of "how things appear to one") but rather a conceptual response grasped via verbal behavior. ${ }^{19}$ Jones' definition of sensation does not refer to any fact or property regarding experience. In fact, the

\footnotetext{
16 Other texts in which Sellars refers to the argument of hallucination include WSNDL, 188 and SRPC $\$ 55$.

17 Although controversial, I think this could also be plausibly defended as a Sellarsian position at an exegetical level. In SSIS, Sellars stresses this aspect in response to Cornman, saying "I have failed to stress this point, however, with the result that I could be taken to imply that the need for sense impressions makes itself felt only after the framework of thoughts as non-verbal inner episodes has been "introduced"" (Ibid.). In this passage, Sellars makes clear that the explanandum is not 'mentalese' (i.e., conceptual activity understood as inner speech).

18 A complete analysis of Sellars' views on perception is not useful for our purposes. For a detailed account, cf. O'Shea (2007), DeVries (2005) and Gupta (2012).

19 "There is $[\ldots]$ a need to postulate sense impressions as part of a general theory of perceptual propositional attitudes in which the propositional component is construed in terms of overt verbal-behavior and propensities to behave" (SSIS, p. 400; cf. also SM, I, 36 and SPR, p. 90).
} 
story does not seem to rely on the notion of experience at all, especially understood as a modification of one's state. The concept of experience and its properties are up to this point left out of the picture. This has important consequences for Sellars' adverbialism, since most criticisms of adverbialism premise their attacks on an experiential definition of sensation. ${ }^{20}$ Second, it is also worth noting that this also applies to phenomenal characteristics of experience: in Sellars' reconstruction, sensation does not name some form of phenomenal given (in the sense of qualia) or aspect of private experience (what it is like to be in a certain state). At least in this context, Sellars maintains that sensations are not phenomenal features or something "inner" 21 but rather states of persons in the MI. Third, it is worth recalling two additional well-known points about Sellars' attempt to de-mentalise sensations: (1) as defined in the proto-theory, sensations are not "intentional". ${ }^{22}$ Furthermore, (2) they are not apperceived (at least certainly not as sensations, and I will try to suggest they are not apperceived at all) (SM, p. 10, FMPP I, §157. I will come back to this issue). This implies that the criticism of adverbialism as "incapable of doing justice" to the essential fact about perception, "namely its intentionality" (Butchvarov, 1980, p. 272), is misplaced for Sellars' theory. In a sense, considering what I have said so far, this criticism is neutralized even before the theory's adverbial characterization even comes to the fore. ${ }^{23}$

At this point, Sellars leaves various aspects of perception still unexplained (putatively intrinsic non-intentional qualitative elements of perception, for instance) or unaccommodated for (e.g., the distinction some contemporary philosophers make between properties of things that appear to us and properties of experience that appear to us), but this openness might represent a positive affordance of Sellars' conceptual genealogy. Indeed, despite its deliberate minimalism, the theory of Jones bears distinct therapeutic import: it preserves the direct realist intuitions of the MI from the threats posed by the argument of hallucination (more on this in Sect. 1.2), and it reveals interpretations of sensation as a given mental item to be non-compelling by providing an alternative, non-problematic interpretation of the notion compatible with the MI. At the same time, the framework leaves room for further qualification of sensation, if necessary, to accommodate additional phenomena (or conceptual issues which have not yet arisen). ${ }^{24}$

\footnotetext{
${ }^{20}$ Cf. Martin (1998, p. 19): "On the adverbialist conception, we are to think of experience as simply being a state of the subject, a way of being modified". The same understanding of adverbialism is shared by Tim Crane, who understands "the qualities sensed in experience to be modifications of experience itself" for the adverbialist (Crane, 2000, p. 177).

${ }^{21}$ It is as misleading to speak of such episodes "as 'inner episodes' as it is to speak of dispositions or propensities as 'in' the things or persons which have them" (SM, p. 169).

22 Sellars has a particular view of intentionality which is not central for my argument here. In general, Sellars considers the conceptual component involved in perception as the bearer of intentionality (modeled on linguistic behavior), cf. DeVries (2005), O'Shea (2007) and Gupta (2012).

${ }^{23}$ However, there are also ways of defending an adverbial conception of intentionality, cf. Kriegel (2008, 2011).

${ }^{24}$ Sellars is aware of this feature: "Jones' theory does not have to be either well-articulated or precise in order to be the first effective step in the development of a mode of discourse which today, in the case of some sense-modalities at least, is extraordinarily subtle and complex. We need, therefore, attribute to this mythical theory only those minimal features which enable it to throw light on the logic of our ordinary language about immediate experiences" (EPM, p. 191). This theory thus appears as the first step in avoiding
} 
Moreover, this minimalist account allows us to take an important additional step: to locate the origins of what I have called the Myth of Sensation. For Sellars, identifying the origin of this second Myth requires analyzing how the Jonesian interpretation of sensation slipped toward understanding the notion as the name for a phenomenal mental given (with a specific categorial status, apperceived as always already having that status, and sometimes given an epistemically justificatory role). Sellars locates this slippage in a mistaken philosophical understanding of the shift from a third-person use of the term to first-person usage. This shift is not interpreted in light of Jones' theory but rather as an expression of acquaintance with some form of Givenness. For Sellars, over time and "under Cartesian pressure" (FMPP, 1981, p. 22), this shift from third to first person produced the "myth of sensation". Yet by correct reconstruction of the original meaning of the notion, we can resist this pressure and avoid getting caught up in the myth. ${ }^{25}$

\subsection{Sensation, direct realism, and the Manifest Image of perception}

It is worth pausing here briefly to recognize that the general conception of sensation introduced thus far is compatible with a form of direct realism, since within this framework "physical objects are really and directly perceived and ... there is no more basic form of (visual) knowledge than seeing physical objects and seeing that they are, for example, red and triangular on this side"(SPR, p. 87). According to Sellars' MI of perception, when all goes well, people directly perceive objects and their properties: under normal circumstances, attending to an object is not a way of being modified in a certain way nor an experience of mere modification. Only in cases of hallucination do sensations enter as part of our explanations to account for our hallucinatory states. This is compatible with a mixed adverbial account of perception, such as the one recently offered by D'Ambrosio (2019, 2021). According to this "new adverbialism", perception is a relational and directed activity but can include adverbial components to account for cases in which it is not successful. ${ }^{26}$ Sellars' account preserves relationality

Footnote 24 continued

certain problems. The strategy leaves further specification of the theory open but seems to place the burden of showing the need for a different understanding of the notion on opponents.

25 Here Sellars agrees once again with Ryle (1956) that the mythological notion of sensation is a philosophical product, created from a more basic, unproblematic framework thanks to pressure exerted by the "profound impact of theoretical science". In his reflections on the history of philosophy, Sellars identifies various steps in this creation story. In SSIS (p. 395), for instance, he describes Locke's distinction between primary and secondary qualities as "a piece of 'revisionary' metaphysics_an early, and clumsy attempt to grasp the transpositions into new categories which the perceptible qualities of the Manifest Image must undergo under the ever more profound impact of theoretical science". In EPM, he describes Descartes' transposition of the qualities of objects into the "mind" along the same lines: "It is a familiar fact that those features of the manifest world which play no role in mechanical explanation were relegated by Descartes and other interpreters of the new physics to the minds (sic) of the perceiver" (PSIM, p. 29). On the application of the Myth of Sensation in the history of philosophy, cf. Barth (2018).

26 Cf. D'Ambrosio (2019, p. 416): “The metaphysics I develop treats adverbial perception as a directed activity: it is an activity with success conditions. When a perception is successful, the agent relationally perceives a concrete particular. But since on my view, perception is not constitutively successful, unsuccessful perception is still perception, and so adverbial perception can be fundamentally non-relational". I will closely analyze the convergence between D'Ambrosio and Sellars' account in the next paragraph. Here I would just like to emphasize that the general strategy is the same as Sellars'. 
in a similar way - at least (and this is key) in cases of actual perception within the MI framework-while sensations enter the picture only in cases of hallucination.

The understanding of Sellars' notion of sensation that I have sketched out so far also moves in the general direction of contemporary realist accounts (Locatelli \& Wilson, 2017), such as the naïve realism and Object View (OV) advocated by Brewer (2011, 2017). Sellarsians would agree with Brewer's formulation of OV:

perceptual presentation irreducibly consists in conscious acquaintance with mind-independent physical objects. It is not to be elucidated or further understood, either in terms of a relation of direct acquaintance with mind-dependent entities that are suitably related to mind-independent things, or in terms of a relation with some kind of representational content (Brewer, 2011, p. 109).

For Brewer, as for Sellars, a relational account is what makes perception intelligible, "with the exception of hallucination" (Brewer, 2011, p. 99). Unlike Brewer and the disjunctivists, however, the Sellarsian line that I have been foregrounding identifies hallucinatory cases as the proper theoretical turf for a specific notion of "sensation" which is not a perceptible factor shared by veridical perception and hallucination but rather a proto-theoretical state that specifically explains hallucinatory conceptual behavior. $^{27}$

\section{Adverbialism about sensations}

Adverbialism is notably a core element of a Sellarsian account of sensation. Traditionally, adverbialism is motivated by the attempt to avoid metaphysical commitment to some controversial perceptible entia non grata (such as sense data) (Jacobson \& Putnam, 2014, p. 556; cf. also Tye, 1984, p. 185). This is certainly at least part of the motivation underwriting Sellars' approach. At the same time, however, another strong reason for adopting adverbialism (e.g., an understanding of sensations as modifications of persons) is that it is naturally consistent with the ontology of the common sense framework in which Sellars' theory of "sensation" was formulated (i.e. the MI, whose basic category is that of persons). Thus the sensational state of "sensing red" is best construed by the term-introducing genius Jones as a state or modification of

\footnotetext{
27 Brewer advances a famous disjunctivist, non-Sellarsian interpretation of hallucinations that eschews the notion of "sensation". According to his view, "hallucinatory experiences have to be characterized by giving a qualitative description of a more or less specific mind-independent scene, and saying that the subject is having an experience that is not distinguishable by introspection alone from one in which the constituents of such a scene are the direct objects. No more positive characterization of the experience may be given" (Brewer, 2011, p. 109). Yet as Brewer himself claims, this is not the only possible account compatible with OV: "although I personally prefer the introspective indistinguishability approach to hallucination (IIH), described above, those who find this unsatisfactory and yet see the broader merits of (OV) may be free to take another track" (Brewer, ibid.). Sellars' story of sensation follows this track, which is compatible with $\mathrm{OV}$ and can be seen as having the advantage of integrating such an account with a coherent interpretation of the notion of "sensation" (Brewer, on the other hand, does not mention sensation in his account; the word is even absent from the index of his book, cf. 2011, 2017).
} 
persons. ${ }^{28}$ Interpreted adverbially, "sensing red" means sensing in a certain manner, i.e., "sensing-redly". In a renowned example, sensing redly is "construed as analogous to waltzing" (SSOS, p. 103): it would be incorrect to describe someone dancing a waltz as if there were two entities, the dancer and the waltz, and an additional relation occurring between them. Rather, dancing a waltz is a manner of dancing (waltzing), which describes a nonrelational state of the dancing person (SM, p. 168; SSOS, p. 103; Conrnman, 1978, p. 69). This conception of persons in certain "states" is naturally embedded in the MI, such that Sellars considers adverbialism-and its typical rephrasing of transitive sentences involving the verb "sense" (e.g., "I sense red") into intransitive adverbial constructions ("I sense redly")—as mere clarification and not a revisionary metaphysics: "I find these adverbial structures clarifying and reject the view that the task of philosophy is to revise" (RA, p. 294).

Notably, adverbialism is not generally regarded as relevant in theories of perception and, until recently, was commonly considered a philosophical dead end. Recently, however, a new debate has emerged around it, which has led to a reappraisal and defense of its basic insights and their philosophical advantages. ${ }^{29}$ Central in this regard has been discussion of the so-called Many-propery Problem (MPP), the problem traditionally understood to have delivered the coup de grâce to adverbial theories and to which most current proponents of adverbialism must offer solutions. If we want to recover some Sellarsian views on sensation, it is then important to ask whether Sellars' views are vulnerable to the MPP? What is Sellars' answer to the problem, and what stances towards it are available to a Sellarsian position as we have constructed it so far?

Before investigating how Sellars did and might have replied to the problem, let me point to a few further, relevant aspects of his view of sensation, which will be essential to grasping Sellars' reply to the MPP. First, as I have shown above, Sellars' adverbialism contains some sui generis features that set it apart from standard adverbial theories. One of them is that sensational states are "thoroughly non-cognitive": their "mediation is causal rather than epistemic" (SPR, p. 91) ${ }^{30}$ As I mentioned earlier, this non-cognitive character implies that we have no awareness of sensations as sensations. This naturally raises the question: what features of sensation cause one to conceptually respond "this is red" and not "this is blue" in the absence of a corresponding object? What is it about sensations that accounts for differentiation in the conceptual response? Jones' theory has an answer that brings the notion of analogy into the picture: states must have properties analogous to the objects which in standard circumstances bring about a particular conceptual response.

These non-conceptual states must have characteristics which, without being colors are sufficiently analogous to color to enable these states to play this guiding role. (SM, p. 18)

\footnotetext{
28 "The only ultimate logical subject involved in a person's having a sense impression of a red rectangle is the person" (SM, p. 169). This marks a further, though minor, difference from other form of adverbialism in which the subjects of the modified state are minds (such as in Tye) or organisms (such as in Jacobson-Putnam).

29 For recent attempts to revive adverbialism, cf. the literature in footnote 5.

30 As Jay Rosenberg puts it: "There is nothing present in her [conceptual response] of which she judges that it is a sense impression" (Rosenberg, 2000, p. 148).
} 
More generally, sensations are states whose characteristics are analogous to the properties of physical objects that in standard cases are conceptually presented in experience. ${ }^{31}$ The analogical interpretation of sensation is introduced by Jones because of its "explanatory power" (ATS, p. 150 and FMPP, p. 72): the analogy constrains and explains the conceptual response associated with the occurrence of a particular sensation. Accordingly, Sellars argues that properties of sensation ("red-ly" and "square-ly") can be derivatively grasped only in terms of properties and predicates of objects in the MI (such as "red", "square", etc.).

Importantly, Sellars stresses that "the analogy is between sense impressions and physical objects and not between sense impressions and perceptions of physical objects" (SPR, p. 93). ${ }^{32}$ This view is consistent with the naïve realist and direct realist insight that the fundamental properties involved in perception (and, in this case, also in non-cognitive sensations) are "to be given precisely by citing and/or describing those very mind-independent physical objects of acquaintance"(Brewer, 2011, p. 94). ${ }^{33}$ Sellars had already endorsed this claim in EPM and in Phenomenalism, arguing for the logical priority of object-talk over look-talk-explaining the latter in terms of the former is essential to his direct realism. ${ }^{34}$

\subsection{The Many Property Problem}

First raised by Jackson (1975), the MPP is one of the main reasons for the abandonment of adverbial theories of perception. It is no surprise then that the resurgence of adverbialism in recent years has gone hand-in-hand with the advancement of various debated solutions to the problem (Banick, 2018; D'Ambrosio, 2019, 2021; Grzankowski, 2018; Kriegel, 2011). In addition, several authors have argued that the MPP applies not only to adverbialism but also to other kinds of theories of perception, including intentionalist ones (Crane-Grzankowski, unpublished; D'Ambrosio, 2021).

In recent discussions, the MPP is usefully interpreted as resulting from the combination of two problems: the expressive problem and the inference problem.

The expressive problem pertains to the correct reformulation, in adverbial terms, of sentences like

\footnotetext{
31 Cf. SK I. 63: "The predicates of the theory of sensing are theoretical predicates, which are introduced in terms of analogy with predicates standing for the proper and commonsensible qualities of physical objects."

32 This means that "the conceptual framework in terms of which common sense conceives these impressions is itself an analogical offshoot from the conceptual framework of physical color and shape" (SRII, pp. 176-177). By postulating a relation between objects belonging to two different categories (manner of sensing and properties of physical objects), the analogy is "transcategorical" (SPR, p. 93). This does not seem to pose any particular conceptual problem. As Sellars emphasizes, "is it absurd to speak of analogies between a dance and a statue?" (ATS, p. 150, fn. 3).

33 The same point can be found in Martin (1998, p. 21): "There seems to be no way to pick out the what it is like properties of the experiences without also picking out corresponding properties which objects may appear to have".

34 This view is by now famous, and I will not dwell on it here. Cf. Levine (2007) for an analysis of Sellars' claim that "one could not have concepts of how things look or appear if one did not already have concepts of how things are". This, however, leaves open the question of the ontological fundamentality of the properties mentioned in discourse. The question of whether "we should give a realistic interpretation" of discourse is separate (ATS, p. 156) and requires a different argument that Sellars presents in FMPP. On this point, cf. Corti (2021).
} 
(a.) Wilfrid senses a green square and red circle.

The issue arises from the fact that the sentence can be paraphrased as

(b.) Wilfrid senses greenly and squarely and redly and circularly.

However, such a paraphrase, which takes the form of a conjunction of adverbial expressions, makes (a.) ultimately indistinguishable from the following sentence

(c.) Wilfrid senses a green circle and a red square,

which can be paraphrased in the exact same way.

To solve this expressive problem, one might consider green and square as forming a distinct syntactic unit, and thus paraphrase the sentence with the adverbial terms "green-squarely" and "red-circularly". The adverbial formulation of (a.) would then become

(d.) Wilfrid senses green-squarely and red-circularly.

This would enable distinction between the two cases (a. and c.), but it raises further problems, since sentence (d.) does not validate inferences intuitive to the original phrasing (such as the move from "Wilfrid senses green-squarely" to "Wilfrid senses squarely"). This is the inference problem.

The scholarly debate has already seen various strategies emerge to approach this issue first raised by Jackson. ${ }^{35}$ Sellars' reply makes clear that he sees the problem located primarily in the ontological and metaphysical assumptions at stake in Jackson's formulation. For Sellars, Jackson seems to understand "sensing" in a way that suggests a person can engage in only one act of sensing at a time-similar to how one can take only one breath at a time. Yet Sellars argues that this is not necessarily the case. ${ }^{36}$ Indeed, considering multiple simultaneous acts of sensing is the only way to have "an intelligible answer to the many property problem" (ATS, p. 147)". In Sellars' words,

the only real hope for an adverbial solution to Jackson's problem requires that' there be a legitimate sense, available to adverbialists, in which [1.] a person can be simultaneously engaged in more than one sensing, and in which [2.] one act of sensing can consist of two or more constituent acts of sensing (ATS, p. 147, my numbering)

The adverbialist must find a way to express such a possibility, and this is what guides Sellars: premised in this assumption, he attempts to articulate an answer to the problem of giving expression of this phenomenon. ${ }^{37}$

As a preliminary move, he introduces two corrections to the above-mentioned formulation (d.) "Wilfrid senses red-triangularly". First, he claims that the correct rephrasing would be to say that Wilfrid senses "a red-triangle-ly", with the article

\footnotetext{
35 For a discussion between "structural" and "non-structural" approaches, cf. Banick (2018) and D’Ambrosio (2021, pp. 827-28 ff).

36 "Perhaps a person can draw only one breath at a time; but if so this seems to be a consequence of what Jackson has packed into the meaning of 'breathe'. Can we not envisage a simultaneous taking of two single-nostrilled breaths?" (ATS, p. 146). This strategy gets taken up by Tye (1989).

37 For an objection to the idea that such a metaphysics is possible. cf. Dinges (2015, p. 236, fn 7).
} 
"a" playing an important role, since it points to the individuation of the sensing state. Second, he stresses that reference to the object is essential to the adverbial reformulation: "a red triangle" must be interpreted as "a red and triangular object" and paraphrased as "(a red and triangular object-)ly"- - which is different from simply saying "red-triangular-ly". ${ }^{38}$ Reference to object locutions is in fact entailed in Sellars' above-mentioned thesis of analogical counterparts, which states that sensations have properties analogous to objects.

Analogy is indeed fundamental for Sellars' entire conception of sensation and is also key to his approach to the MPP problem, because he considers the individuation of a sensation possible in terms of the properties of the object that in standard circumstances cause a conceptual response (Tye, 1975). In visual sensations, for instance, the structures and compositions of sensations reflect the structures and compositions of objects that in standard cases (such as seeing) are present in the visual field. In the context of sensation, then, the concept of relations among objects in the visual field is translated into adverbial terms, so "clearly what we need is two-place adverbs pertaining to sensory states" (ATS, p. 153). Sellars acknowledges that such a theory remains largely promissory and still needs to be properly elaborated. Still, the direction in which he is tries to move to work out a solution is clear and based on an extension of the analogical intuitions of the mythological Jones: not only do sensations have properties analogous to the objects that cause them, but they also stand in relation to each other in ways that are analogous to the relation among the corresponding objects.

For example, Sellars introduces the adverbial predicate "adjoinigly" as the counterpart of "adjoining" understood as the relation among objects in space. ${ }^{39}$ The upshot of his view is that "the composition of sensations, thus, is the counterpart of the composition of the objects which are their proper causes" (ATS, p. 154). In this way Sellars thinks he can "specify identity conditions for sensations with respect to a person $\mathrm{P}$ and a time t" (ATS, p. 154). ${ }^{40}$ Although the appropriate general ontology of events and states must still be elaborated, Sellars maintains that this general direction offers a way out of the inference problem represented by the MPP. ${ }^{41}$

With these assumptions in place, we can better grasp Sellars' answer to the two above-mentioned problems. In response to the expressive problem, he maintains that relations among sensations must be expressed via specifically regimented counterpart predicates. In other words,

(a.) Wilfrid senses a green square and red circle.

must be rephrased as

\footnotetext{
38 For Sellars, Jackson misleads "by dropping the 'a' and, what is more important, by changing 'triangle' to "triangular"' (ATS, p. 149).

39 "In the theory 'adjoining-ly' is the two-place adverb which applies to sensings normally brought about by adjoining objects (e.g. a red square one side of which coincides with a side of a blue square)" (ATS, p. 154).

40 "In other words, two visual sensations of $\mathrm{P}$ at $\mathrm{t}$ are identical if and only if every sensory attribute of each belongs to the other." (ATS, p. 155).

41 Sellars elaborates this ontology in later essays such as FMPP. Reconstructing it is beyond the scope of this paper.
} 
(e.) Wilfrid senses (a green and square object)-ly adjoining-ly (a red and circular object)-ly. ${ }^{42}$

Sellars thinks that mentioning "object" in the locution "(a green and square object)-ly" is "essential to preserve the structure" (ATS, 154). Preserving the structure-i.e., assuming the analogy of counterparts and relations between objects and sensations-allows us to validate the right inferences, since for Sellars, according to the hypothesis proposed, the conceptual properties of "green" and "square" in an adverbial context "are conveyed by the fact that these same words in physical object discourse stand for an attribute having analogous conceptual properties" (ATS, p. 150). This enables Sellars to claim that "we can justify treating adverbial expressions pertaining to visual sensations as syntactically composite and subject them to the desired logical manipulations" (Ibid., p. 160)—and thus solve the inference problem.

Such a view is far from uncontroversial: the fact that it is based on the simple postulation of a structural analogy may appear to some, in Sellars' words, to be "theft instead of honest toil" (ATS, 155). ${ }^{43}$ However, what my reconstruction brings to the fore is that Sellars' views are compatible with (and developed along the same line as) some current strategies for solving the MPP, including the one recently endorsed by D'Ambrosio (2019, 2021). At a general level, the solution provided by D'Ambrosio is built upon an understanding of "sensing" as conceptually dependent on "seeing". D'Ambrosio conceives this dependence in terms of success conditions, essentially formalizing the idea that successful (i.e., accurate) sensing is seeing (D'Ambrosio, 2021, p. 822). Without going into the details of D'Ambrosio's analysis, which would be beyond the scope of this paper, we can still identify this assumption as a) first enabling him to construe seeing as essentially relational and b) second specifying sensing in terms of seeing. In this way, D'Ambrosio "takes relational seeing as explanatorily fundamental" (ibid., p. 811). Furthermore, and most importantly, this conception postulates a structural link between discourse on sensing and discourse on seeing, to the extent that the properties of the first can be specified and expressed in terms of the second and thus solve the MPP. D'Ambrosio formalizes the following strategy:

by specifying accuracy conditions for Mary's sensation, the analysis ... shows how structural relationships between properties yield logical relationships between states of sensing those properties, thus validating upward monotonicity, and solving the inferential problem (D'Ambrosio, 2021, p. 823).

This strategy is also open to Sellars, at least in the views that I have reconstructed so far. Again, when all goes well, for Sellars the subject perceives the world in a relational way. In cases of hallucinations, the subject instead "senses". This state is construed as structurally analogous to seeing, such that inferences in seeing speech can be validated in sensing speech-since, as D'Ambrosio argues, in contexts such as "the case of a

\footnotetext{
42 ATS, p. 154. This solution is similar to the one proposed by Tye (1984).

43 It is furthermore unclear whether this position is vulnerable to further objections, such as the reemergence of the MPP in the form of the Many Relation Problem (Dinges, 2015).
} 
hallucination, there simply is no object to which the hallucinating subject is related. This captures the main desiderata on an adverbial view of perception" (Ibid., p. 831). ${ }^{44}$

\subsection{Criticism}

At this point, some scholars may object that my interpretation moves beyond Sellars and, in a substantial way, against his approach. In fact, in many passages Sellars seems to extend the Myth of Jones to claim that "sensations" are present in all perception. He thus appears to defend "the idea that visual perception always involves sense impressions" (SM, p. 15, my emphasis) and that "direct perception of physical objects is mediated by the occurrence of sense impressions" (ATS, p 150; cf. also SPR, p. 90). I do not want to deny that this line of thought can be identified in Sellars. As my reconstruction suggests, however, these claims are an extension of Sellars' original Ryleian argument rather than a necessary consequence of it (the myth gets enriched with the idea that sensation mediates not only cases of hallucination but also episodes of veridical perception). It is moreover important to notice that this extension is not logically entailed by the myth's premises or the Sellarsian argument I have reconstructed, and therefore-even if a position Sellars eventually endorses-it must be argued for on independent grounds. It is these grounds that we might want to question.

For instance, commitment to the claim that sensation mediates all perception (and not only hallucinations) may require acceptance of a stronger 'common factor' conception of experience, which, added to what we have seen so far, would lead to considering sensations a constitutive part of veridical experience. However, this is not necessarily so. Similarly, there may well be an argument present in Sellars independent of the Jonesian myth that leads to the same conclusion. Nonetheless, for our purposes what is worth noting is that the claim "sensation always mediates perception" does not come from the argument about hallucination analysed above but from a different route. If extending sensations to normal cases is not philosophically compelling, then Sellars' alleged commitment to sensation as always involved in perception can be resisted: the mediation of sensation in all experience is not part of the core of Jones' theory, which allows us to reject this claim and still retain a coherent Sellarsian adverbial take on sensation. ${ }^{45}$ Our resulting theory still preserves all relevant explanatory significance and can perform its therapeutic role.

\footnotetext{
44 The structural link between seeing and sensing that preserves the monotonicity of inference between the two domains is secured in D' Ambrosio by the notion of "success" (in any world in which the act of sensing is successful, the subject is seeing), whereas in a Sellarsian framework the structural link supporting the validation of the correct inferences is secured by the notion of "analogy". This aspect is certainly in need of further development, however, and lays beyond the aims of this paper, which instead aims to reconstruct and defend the consistency of Sellars' overall approach to the issue.

45 Another way of arguing for my point might be the following: regarding the question of supporting the extension of sensation to normal cases, Sellars argues that "even in normal cases there is the genuine question: 'Why does the perceiver conceptually represent a red (blue etc.) rectangular (circular etc.) object in the presence of the object having these qualities?"' (SM, p. 18, my emph). In my view, one might resist this question by asking: what makes this a genuine question? In what scenario is this problem genuine? Certainly not in Jones' common sense framework, where this instead appears to be an empty question and not a query that calls for an answer. For without the emergence of some additional facts or reasons that would make veridical perception problematic in a Jonesian scenario, i.e., in normal cases, one directly perceives objects as having certain qualities - and thus no sensational mediation is needed. Here I agree
} 


\subsection{Sensation and phenomenal properties}

In the reconstruction above, the definition of impressions does not include "phenomenal properties" of experience. Interestingly, what today's scholars call sensational content (i.e., intrinsic, perceptible non-conceptual properties of experience) does not fall under the Sellarsian heading of "sensation", at least not directly. The separate treatment of the two issues - sensation, one one hand, and phenomenal aspects on the other-is part of Sellars' strategy for avoiding conceptual confusion and the insurgence of problematic mythological accounts. However, understood in the general sense, phenomenal features are a constitutive part of perception, which makes the ability to account for them one of the criteria for evaluating the adequacy of a theory of perception. The question thus arises: in following the Sellarsian approach that I have outlined, how should one account for these features of perception? Sellars himself acknowledges, after a phenomenological analysis, that perceptions are characterized by particular sensory modalities:

phenomenologically speaking, the descriptive core consists in the fact that something in some way red and triangular is in some way present to the perceiver other than as thought of (SK, I.55).

This claim is the conclusion of a well-known argument that starts with the difference between "seeing x" and "believing x"46 and maintains that the distinctive feature of the former is it involves something like a perceptual presence (something somehow present in perception other than thoughts). How should we conceive of this phenomenal element?

To understand Sellars' response, we should take a step back to consider what Sellars means by phenomenological analysis. What does he think one learns by performing a phenomenological analysis of one's experience? Here Sellars' reflections move in a direction that is again compatible with direct realism: he does not consider phenomenological analysis a special kind of direct inspection or introspection of an element of our experience-i.e., what Tye calls a "quasi-scanning process" (Tye, 2002, p. 144). Rather, the phenomenologist brackets the causal and dispositional properties of the presented objects, as well as some other categorial features of perception. However, doing so does not result in discovery of new entities but in removal of categories

\section{Footnote 45 continued}

with Gupta (2012, p. 37) that Sellars' insistence on the above-mentioned question is motivated by his naturalism (which is something additional with respect to our story). On the other hand, one might insist that different arguments supporting the idea that sensation is always involved in perception can be found in Sellars. Coates (2007, Chap. 1) reconstructs one of them under the heading 'Substraction Argument'. This argument starts from a claim Sellars seems to make in some later texts, namely that the explanandum for sensation is not verbal behavior, as in the Myth of Jones, but rather the qualitative phenomenal features of experience (SRPC § 41). I agree that this argument is present in Sellars, but for my purposes it is sufficient to note that it is a different argument (with different premises and different explanandum) —one which leads Coates to identify sensation with the phenomenal properties mentioned above (cf. footnote 16). I have no space to argue against this reading here, but it is sufficient to acknowledge that the argument I lay out is different, coherent, and not problematic and does not require response to Coates' substraction argument. The fact that Sellars does not clearly distinguish between the two arguments may generate some confusion. 46 "There is all the difference in the world between seeing something to be a pink ice cube, and merely thinking something to be a pink ice cube." (SK, p. 306). 
that are embedded in perception and pertain to physical object discourse. This is an important aspect of Sellars' account.

We, as phenomenologists, can bracket the concept of an expanse of red in that radical way which involves an abstraction from all those implications involved in being the concept of something physical. But by so abstracting we do not acquire a concept of red which belongs to a more basic determinate category-we simply abstract from such determinate categorial status it has, and construe it merely as a particular having some determinate categorial status or other. Our phenomenological abstraction no more reveals a new determinate category than the concept of some color or other generates the concept of a new shades of red (FMPP, p. 20, my emph.)

As Jay Rosenberg summarizes, "the phenomenological attitude brackets causal and dispositional properties and the like, but does not shift the sense of sensory quality predicates" (Rosenberg, 2000, p. 146), ${ }^{47}$ which are originally defined as predicates of physical objects. The predicates by which one describes and grasps the phenomenology of one's experience are thus predicates that pertain to physical objects. ${ }^{48}$

In general, this view is consistent with the direct realist intuitions distinctive of the MI of perception and importantly avoids the perplexity connected to the idea of purely phenomenal properties. The result is an account of the structure of perception that gives strong priority to what, in contemporary terms, can be called "presented elements" over "phenomenal properties" (Martin, 1998, p. 21). This view, however, does not imply that experience is completely transparent or diaphanous (i.e., that differences in phenomenal properties are only differences in presented elements) but-to continue with this non-Sellarsian vocabulary - claims that any specification of phenomenal properties can only be made in terms of properties (i.e., predicates) of presented elements. Understood in this way, a Sellarsian view therefore appeals to the set of arguments on the transparency of experience deployed by direct realists.

A last question might arise at this point: should these phenomenal features of perception be identified with what, in a different line of argument, we have called "sensations"? There seems to be no need to make this connection. Logically, the two lines of argument are separable (Sellars seems to keep them separate), ${ }^{49}$ and nothing of what we have said so far requires integrating them. Though Sellars seems to suggest in more than one place that there is a link between his "theory of sensation" and philosophical reflection on perceptible properties, ${ }^{50}$ there is no philosophical need to connect them. The pressure to unify these frameworks again seems to have

\footnotetext{
47 Misunderstanding this point leaves philosophers like C.I. Lewis in the grips of the Myth of the Given, since they isolate characteristics of experience as having a presumed original categorial status of "quale".

48 Rosenberg (2000, pp. 145-146) stresses this point: "What is crucial to this picture, emphasizes Sellars, is that the 'ur-concept' of red is not that of an aspect or element of an experience but 'the concept colors, is the very stuff of which physical objects are made"" (FMPP, p. 15).

49 "It is by the introduction of ... sensations that we transcend phenomenology ... They are not yielded by phenomenological reduction, but postulated by a proto-(scientific) theory" (SRPC, p. 179, my emph.).

50 As for instance when he claims: "If we are aware of states of sensing bluely, we are, at best, aware of them as blue items - cases of blue — and not as states of ourselves" FMPP, p. 67. Notice, however, that Sellars writes at best but does not endorse the claim as necessary.
} 
different sources which can be rejected or resisted as unnecessary. Also because, as suggested above ( $\$ 2)$, keeping the framework of sensation separable from the analysis of phenomenal content enables Sellars to diagnosis the problems around sensation, which can be treated as arising precisely from attempts to merge-for one reason or another-the two levels of analysis (confusing the logical dimension of sensation with the logical dimension of phenomenal content). I will not analyze here how such confusions might be accounted for. It is sufficient to emphasize that there does not seem to be any particular pressure to correlate the two lines of argument. ${ }^{51}$

At an exegetical level, this is another point at which my Sellarsianism might be seen as a heterodox departure from Sellars texts in order to pursue a promising line of argument that is followed on in a Sellarsian spirit. As I hope to have demonstrated, however, the line of Sellars' thought that I follow reveals how talk of "sense impressions" might have arisen and clarifies how it might have gone wrong, while also pointing to a non-problematic way of understanding sensation. ${ }^{52}$ This is exactly what Sellars' reflections on sensations aimed to achieve.

\section{Conclusions}

In this paper, I have presented a reconstruction of Sellars' adverbialist account of sensation. Keeping in mind his general philosophical method of exploring conceptual frameworks, I have surveyed his adverbialist approach to the notion. I have focused in particular on the Myth of Jones and the argument it contains, unfolding some of its core insights - while showing that others can be resisted-in order to establish it as a viable account of sensation.

In the Sellarsian approach that I have presented, adverbialism about sensation can be integrated into a broader relational conception of experience in which sensation is introduced to perform a particular explanatory role. According to this view, in the MI perception is relational, but cases of hallucination justify the introduction of the notion of "sensation", which is best understood in adverbial terms. The insights developed in articulating this point are consistent, in a specific sense that I have clarified, with those presented by proposals of a "new adverbialism” such as D' Ambrosio's (2019, 2021).

In the account I have presented, the notion of "sensation" is introduced and defined in a way that does not expose it to standard criticisms of adverbialism, especially those related to insufficiently accounting for intentionality and the phenomenal character of experience-which I have addressed in the last part of this paper. As heterodox as it may be, my approach is nonetheless recognizably Sellarsian in its emphasis of arguments that are crucial to his account.

\footnotetext{
51 The question regarding their integration is interesting. What would properly integrating them amount to? Would one need an additional theory that connects blue as a phenomenal property (as accounted for in phenomenological bracketing) with the sensation of blue as a theoretical entity postulated by Jones? These questions are beyond the scope of my paper, which aims to show the separation of the two as logically consistent. However, once the separation has been established, the issue can be further explored.

52 As some scholars have argued, Sellars has "a good deal to say that strongly suggest he would find no use for such notion, at least in the way it is usually understood" (Leeds, 1993, p. 308).
} 
As Sellars himself notices, this "framework of sense impressions is not a formalized theory," which implies that its "force and limitations...must be tickled out piecemeal by exploring the logic of sample uses of the framework." (SPR, p. 93). Further scholarship is necessary to deepen and widen this Sellarsian framework in both historical and theoretical terms, to refine it, and to address philosophical uses of 'sensation' in the past and present. As I have pointed out, further work is also necessary to explore the notion's conceptual apparatus, including the relation between sensation and phenomenal experience that I have excavated. ${ }^{53}$ Sellars is convinced that his treatment of the "broad issues of philosophical strategy, and even a large-scale map of the jungle of perceptual epistemology can bring decisive clarification" (SPR, p. 93). Starting from this premise, I hope to have shown how a Sellarsian approach to sensation can point us towards a both explanatorily adequate and metaphysically acceptable account of this notion.

Funding Open access funding provided by Università degli Studi di Padova within the CRUI-CARE Agreement. This project has received funding from the European Union's Horizon 2020 research and innovation programme under the Marie Skłodowska-Curie grant agreement No 845937. Acronym of the project: NINA.

Open Access This article is licensed under a Creative Commons Attribution 4.0 International License, which permits use, sharing, adaptation, distribution and reproduction in any medium or format, as long as you give appropriate credit to the original author(s) and the source, provide a link to the Creative Commons licence, and indicate if changes were made. The images or other third party material in this article are included in the article's Creative Commons licence, unless indicated otherwise in a credit line to the material. If material is not included in the article's Creative Commons licence and your intended use is not permitted by statutory regulation or exceeds the permitted use, you will need to obtain permission directly from the copyright holder. To view a copy of this licence, visit http://creativecommons.org/licenses/ by/4.0\%.

\section{References}

Banick, K. (2018). How to be an adverbialist about phenomenal intentionality. Synthese, 198(21), 661-686.

Barth, K. (2018). Sellars on Descartes. In L. Corti \& A. M. Nunziante (Eds.), Sellars and the history of modern philosophy. Routledge.

Brewer, B. (2011). Perception and its objects. Oxford University Press.

Brewer, B. (2017). The object view of perception. Topoi, 36, 215-227.

Butchvarov, P. (1980). Adverbial theories of consciousness. Midwest Studies in Philosophy, 5(3), 261-280.

Christias, D. (2014). An interpretation and extension of Sellars's views on the epistemic status of philosophical propositions. Metaphilosophy, 45(3), 348-371.

Coates, P. (2007). The metaphysics of perception: Wilfrid Sellars, perceptual consciousness and critical realism. Routledge.

Conrnman, J. (1978). Sellarsian scientific realism without sensa. In J. C. Pitt (Ed.), The philosophy of Wilfrid Sellars: Queries and extensions. D. Reidel.

Corti, L. (2021). The notion of sensation in Sellars' theory of perception. European Journal of Philosophy, 29(4), 1079-1099.

Crane, T. (Ed.). (1992). The contents of experience. Cambridge University Press.

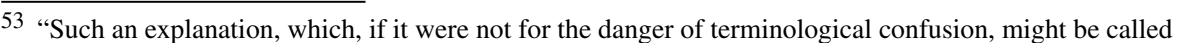
the phenomenology of sense impressions, is an hardous and time consuming task which lies beyond the scope of this discussion (Ibid.)."
} 
Crane, T. (2000). The origins of Qualia. In T. Crane \& S. Patterson (Eds.), History of the mind-body problem (pp. 169-194). Routledge.

Crane, T. (2006). Is there a perceptual relation? In T. S. Gendler \& J. Hawthorne (Eds.), Perceptual experiences (pp. 126-146). Oxford University Press.

D’Ambrosio, J. (2019). A new perceptual adverbialism. Journal of Philosophy, 116(8), 413-446.

D'Ambrosio, J. (2021). The many-property problem is your problem, too. Philosophical Studies, 178, 811-832.

Dach, S. (2018). Sellars's two images as a philosopher's tool. Metaphilosophy, 49, 568-588.

deVries, W. A. (2005). Wilfrid Sellars. Acumen.

deVries, W. A. (2006). Folk psychology, theories, and the Sellarsian roots. In M. P. Wolf \& M. N. Lance (Eds.), The self-correcting enterprise: Essays on Wilfrid Sellars (pp. 53-84). Rodopi.

Dinges, A. (2015). The many-relations problem for adverbialism. Analysis, 75(2), 231-237.

Garfield, J. (1989). The myth of Jones and the mirror of nature: Reflections on introspection. Philosophy and Phenomenological Research, 50, 1-26.

Gert, J. (2021). Information-theoretic adverbialism. Australasian Journal of Philosophy, 99(4), 696-715.

Grzankowski, A. (2018). The determinable-determinate distinction can't save adverbialism. Analysis, 78(1), $45-52$.

Gupta, A. (2012). A critical examination of Sellars's theory of perception. In M. Frappier, D. Brown, \& R. DiSalle (Eds.), Analysis and interpretation in the exact sciences (pp. 31-56). Springer.

Hicks, M. R. (2020). Wilfrid Sellars and the task of philosophy. Synthèse, 198(10), 9373-9400.

Jackson, F. (1975). On the adverbial analysis of visual experience. Metaphilosophy, 6(2), 127-135.

Jacobson, H., \& Putnam, H. (2014). The needlessness of adverbialism, attributeism and its compatibilty with cognitive science. Philosophia, 42, 555-570.

Kriegel, U. (2007). Intentional inexistence and phenomenal intentionality. Philosophical Perspectives, 21, $307-340$.

Kriegel, U. (2008). The dispensability of (merely) intentional objects. Philosophical Studies, 141, 79-95.

Kriegel, U. (2011). The sources of intentionality. Oxford University Press.

Kukla, R. (2000). Myth, memory and misrecognition in Sellars' empiricism and the philosophy of mind. Philosophical Studies, 101(2-3), 161-211.

Leeds, S. (1993). Qualia, awareness, Sellars. Nô̂s, 27(3), 303-330.

Levine, S. (2007). Sellars' critical direct realism. International Journal of Philosophical Studies, 15(1), $53-76$.

Levine, S. (2016). Sellars on non-conceptual content. European Journal of Philosophy, 24(4), 1-24.

Locatelli, R., \& Wilson, K. A. (2017). Introduction: Perception without representation. Topoi, 36, 197-212.

Lyons, J. (2009). Perception and basic beliefs: Zombies, modules, and the problem of the external world. Oxford University Press.

Martin, M. G. F. (1998). Setting things before the mind. In A. O'Hear (Ed.), Current issues in philosophy of mind. Cambridge University Press.

McDowell, J. (2009). Having the world in view: Essays on Kant, Hegel, and Sellars. Harvard University Press.

Mendelovici, A. (2018). The phenomenal basis of intentionality. Oxford University Press.

O'Shea, J. (2007). Wilfrid Sellars: Naturalism with a normative turn. Polity Press.

O'Shea, J. (2012). The 'theory theory' of mind and the aims of Sellars' original myth of Jones. Phenomenology and the Cognitive Sciences, 11, 175-204.

O'Shea, J. (2021). What is the myth of the given? Synthese, 199, 10543-10567.

Peacocke, C. (1983). Sense and content. Experience, thought and their relation. Clarendon Press.

Richardson, R. C., \& Muilenburg, G. (1982). Sellars and sense impressions. Erkenntnis, 17(2), 171-211.

Rosenberg, J. (2000). Perception vs. inner sense: A problem about direct awareness. Philosophical Studies, 101(23), 143-160.

Rosenberg, J. (2007). Wilfrid Sellars: Fusing the images. Oxford University Press.

Ryle, G. (1949). (COM) The concept of mind. Routledge.

Ryle, G. (1956). Sensation. In: Collected papers (2 Vols., pp. 349-361). Routledge.

Ryle, G. (1971). (CP). Collected papers (2 Vols.). Routledge.

Sellars, W. (1952). (P). Particulars. In his Science, perception and reality (1963). Ridgeview.

Sellars, W. (1956). (EPM). Empiricism and the philosophy of mind. Reprinted in his Science, perception and reality (1963). Ridgeview.

Sellars, W. (1963). (SPR). Science, perception and reality. Ridgeview. 
Sellars, W. (1965) (SRII). Scientific realism or irenic instrumentalism: A critique of Nagel and Feyerabend on theoretical explanation. In Boston studies in the philosophy of science (Vol. II, pp. 171-204). Humanities Press.

Sellars, W. (1967). (RA). Reply to Aune. In H.-N. Castañeda (Ed.), Intentionality, minds and perception (pp. 286-300). Wayne State University Press.

Sellars, W. (1968). (SM). Science and metaphysics: Variations on Kantian Themes. Ridgeview.

Sellars, W. (1971). (SSIS). Science, sense impressions, and sensa: A reply to Cornman. Review of Metaphysics, 25, 391-447.

Sellars, W. (1975a). (ATS). The adverbial theory of the objects of sensation. Metaphilosophy, 6(2), 144-160.

Sellars, W. (1975b). (SK) The structure of knowledge: (1) perception; (2) minds; (3) epistemic principles. In H.-N. Castaneda (Ed.), Action, knowledge and reality: Studies in honor of Wilfrid Sellars (pp. 295-347). Bobbs-Merrill.

Sellars, W. (1978). (SRPC). Some reflections on perceptual consciousness. In R. Bruzina \& B. Wilshire (Eds.), Crosscurrents in phenomenology (pp. 169-185). Kluwer.

Sellars, W. (1981). (FMPP). Foundations for a metaphysics of pure process. The Carus Lectures. The Monist, 64, 3-90.

Sellars, W. (1982). (SSOS). Sensa or sensings: Reflections on the ontology of perception. Philosophical Studies, 41(1), 83-111.

Tanney, J. (2013). Ryle's conceptual cartography. In E. H. Reck (Ed.), The historical turn in analytic philosophy. Palgrave-Macmillan.

Triplett, T., \& DeVries, W. A. (2006). Is Sellars's Rylean hypothesis plausible? A dialogue. In M. P. Wolf \& M. N. Lance (Eds.), The self-correcting enterprise: Essays on Wilfrid Sellars (pp. 53-84). Rodopi.

Tye, M. (1975). The adverbial theory: A defense of Sellars against Jackson. Metaphilosophy, 6(2), 136-143.

Tye, M. (1984). The adverbial approach to visual experience. The Philosophical Review, 2, 195-225.

Tye, M. (1989). The metaphysics of mind. Cambridge studies in philosophy. Cambridge University Press.

Tye, M. (2002). Representationalism and the transparency of experience. Nous, 36(1), 137-151.

Tye, M. (2003). A theory of phenomenal concepts. In A. O’Hear (Ed.), Minds and persons (pp. 91-106). Cambridge University Press.

Publisher's Note Springer Nature remains neutral with regard to jurisdictional claims in published maps and institutional affiliations. 